\title{
Correlation of Placental Thickness in Relation to Gestational Age and Fetal Weight by using Ultrasonography
}

\author{
Muraliswar Rao $\mathrm{J}^{1}$, Anil Kumar Kallepally ${ }^{2}$ \\ Associate Professor, Department of Radiodiagnosis, ${ }^{2}$ Assistant Professor, Department of Radiodiagnosis, Maharaja Institute \\ of Medical Sciences Vizainagaram, India
}

Corresponding author: Dr anil Kumar Kallepally, Sri Kallepalli Home, D No 6-16-8, East Point Colony, Visakhapatnam 530017, India

DOI: http://dx.doi.org/10.21276/ijcmsr.2019.4.3.30

How to cite this article: Muraliswar Rao J, Anil Kumar Kallepally. Correlation of placental thickness in relation to gestational age and fetal weight by using ultrasonography. International Journal of Contemporary Medicine Surgery and Radiology. 2019;4(3):C135-C140.

\section{A B S T R A C T}

Introduction: Abnormalities in placental thickness are well known as a diagnostic predictor in a wide spectrum of pathologic events. Study on placental thickness can contribute to at risk fetus management. Previous studies proved the role of placental thickness in estimating gestational age.Measurement of Placental thickness can help in differentiating normal from abnormal pregnancy. Thickness of placenta is closely related to wellbeing of fetus and may be an important factor in predicting perinatal outcome.

Material and methods: A Cross-sectional descriptive study was carried out in the Department of Radiology, MIMS, Vizianagaram over a period of one year from January 2018 to December 2018.Ninety-nine normal antenatal women of all gestational ages from 11 weeks to 40 weeks of gestation were included in the study. Prior informed consent was obtained. Ultrasonogram was used to assess thickness of placenta, gestational age and fetal weight. Relation between gestational age, placental thickness and expected birth weight was computed separately for second and third trimesters using Pearson's correlation.

Results: At gestational age of 11-35 weeks, there was no statistically significant difference between the mean of gestational age (18.97 \pm 8.02$)$ and placental thickness $(19.02 \pm 8.00)$ and there is a high degree positive correlation between gestational age and placental thickness $(r=0.989)$ which was highly significant. At $>35$ weeks of gestational age, there is a statistically significant difference between the mean of gestational age (37.53 \pm 1.45$)$ and placental thickness $(35.33 \pm 1.44)$ and there is a poor degree positive correlation between gestational age and placental thickness $(r=0.248)$ which was also statistically not significant.Statistically significant positive correlation was observedyielding a Pearson's correlation coefficient $(r)$ of 0.902 and 0.856 for the second and third trimesters respectively.

Keywords: Placental Thickness, Gestational Age, Fetal Weight, Ultrasonogram

\section{INTRODUCTION}

Placenta is mainly a fetal organ and its size reflects the health and size of the fetus. Placental size is an ultrasonographic parameter frequently used to assess the placenta. Total placental volume is probably the most accurate estimate of placental size, but volumetric measurement is too complicated and cumbersome for routine use. ${ }^{1}$

Abnormalities in placental thickness are well known as a diagnostic predictor in a wide spectrum of pathologic events. Study on placental thickness can contribute to at risk fetus management. ${ }^{2}$ Previous studies proved the role of placental thickness in estimating gestational age. Measurement of placental thickness can help differentiate normal from abnormal pregnancy. ${ }^{3}$ Gestational age can be estimated by ultrasonography (USG) by measuring the foetal dimensions like the Biparietal Diameter (BPD), the Abdominal Circumference (AC), the Head Circumference (HC) and the Femur Length (FL). An ultrasonogram is prone to observer bias, as it depends on the observers' technical skills. Also, the foetal parameters, the different techniques of measurement and the positional problems may diminish the accuracy of the gestational age estimation. ${ }^{2}$

Studies showed that the biparietal diameter was not reliable in the foetuses which had a premature rupture of the membranes.Drawbacks in the above said parameters in estimating the gestational age have been reported ${ }^{3}$ Hence, there is a need for different parameter for assessment of the gestational age with minimal error. Nyberg and Finberg ${ }^{4}$ reported that the placental thickness parallels the gestational age.

Medical imaging modalities used for fetal weight estimation include magnetic resonance imaging (MRI) and ultrasonography, the latter being the more popular modality. Fetal weight estimates are very important because a large proportion of perinatal mortality is related to birth weight. Obstetric ultrasonography offers the tools to estimate the fetal weight and assess placental size.Indeed, placental disease has 
been shown to be the most clinically relevant of all potential underlying processes that may result in intrauterine growth restriction. ${ }^{5}$

Thickness of placenta is closely related to wellbeing of fetus and may be an important factor in predicting perinatal outcome. Large placentas are associated with hemolytic disease of newborn, maternal diabetes mellitus, severe anemia and intrauterine fetal infections. ${ }^{6,7}$ Small placentas are associated with preeclampsia, chromosomal abnormalities, severe diabetes mellitus, chronic fetal infections and intrauterine growth restriction. ${ }^{6,8,9}$

The purpose of the present study of is to evaluate if placental thickness could be used as an alternative parameter to determine fetal gestational age and weight whenever routine fetal biometry could not be carried out.

\section{Objectives}

1. To evaluate the utility of placental thickness in determining age of fetus and compare it with the age obtained by fetal biometry using correlation analysis.

2. To evaluate the utility of placental thickness in determining weight of fetus and compare it with the weight obtained by fetal biometry using correlation analysis.

\section{MATERIAL AND METHODS}

A Cross-sectional descriptive study was carried out in the Department of Radiology, MIMS, Vizianagaramover a period of one year from January 2018 to December 2018. The study population included normal antenatal women referred from antenatal clinic at the department of Obstetrics and Gynaecology to the Radiology department for routine antenatal ultrasound.

The correlation between placental thickness and gestational age in the 1st trimester was found to be high, 0.609 (r) from the previous published article by $\mathrm{T}$ Karthikeyanet al. ${ }^{10}$ Considering the $99 \%$ level of confidence interval $(Z \alpha / 2=2.576)$ with $90 \%$ power $(Z \beta=1.282)$ the minimum required sample size is 33 . There are three main groups in this study namely First, Second and Third Trimesters. Therefore, the minimum required sample for the study is 99 .

Normal antenatal women of gestational ages ranging from 11 weeks to 40 weeks were included in the study. 20 and Prior informed consent was obtained. Participants with $\mathrm{PIH}$, diabetes mellitus, intrauterine growth restriction, hydropsfetalis, congenital malformations, twins, Polyhydramnios, Oligohydramnios and those with abnormal placental morphologies like lobed placenta, succenturiate lobe, placenta membranacea and circumvallate placentas, marginal or battledore placentas and velamentous cord insertions and those participants who did not give informed consent were excluded from the study.

After explanation of the reason and purpose of the study, an informed consent was obtained.Placental thickness, gestational age and fetal weight were recorded ultrasonologically after taking a detailed history from the antenatal women. The Ultrasound Scanners and Transducers that were used: The grey scale real time ultrasonographic examinations were performed using a PHILIPS AFFINITY 30 ultrasound scanner and the probe used for the study was $3.5 \mathrm{MHz}$ convex array transducer. Hard copy images of the cases were obtained using thermal printer and photographs.

The participants were scanned with a moderately distended bladder in supine position. The transducer was then placed on the surface of skin after applying coupling agent. The placental thickness in $\mathrm{mm}$ was assessed at the level of cord insertion site. Placental thickness was measured from echogenic chorionic plate to placental myometrial interface. All placental measurements were recorded during the relaxed phase of the uterus as contractions can show a spurious rise in the placental thickness. CRL measurement and Hadlock tables were used to assess the gestational age in first trimester from 11 to 13 weeksof pregnancy. ${ }^{11}$ Other measurements are not more accurate than CRL length in predicting gestational age from 11 to 13 weeks and their use in combination with CRL does not further improve age estimation ${ }^{12}$ Composite fetal measurements of BPD, $\mathrm{HC}, \mathrm{AC}$, and $\mathrm{FL}$ were used to measure the gestational age in second and third trimesters from 14 to 40 weeks of pregnancy. ${ }^{13}$ Gestational age was measured by the ultrasound machine based on Hadlock tables by using regression equations from combination of measurements. In second and third trimesters, fourparameter method used resulted in lowest variability estimates. Use of multiple variables would reduce uncertainty of the prediction, especially when measurements are made for the first time in the third trimester. ${ }^{14,15}$

Sonographic measurements of body parts of fetus provide a direct way of assessing size of fetus. Several formulas have been published for assessing fetal weight from one or more of the following fetal body measurements: head (BPD, HC), abdomen (AC) and femur (FL). Other measurements, such as thigh circumference have also been used. ${ }^{16}$ Formulas that estimate fetal weight usingthree-dimensional (3D) sonography and 3D magnetic resonance imaging have also been published. ${ }^{17}$

The Statistical software namely, SPSS 21.0 was used for the analysis of the data and Microsoft word and Excel were used to generate graphs, tables etc. The data was analysed 32 by calculating the descriptive statistics such as mean and SD for continuous variables. The Pearson's Correlation ( $\mathrm{r}$ value) was carried out to show the relation between the gestational age in weeks and Placental thickness in $\mathrm{mm}$. Student's unpaired t-test was used to find out the differences between two gestational age groups (11-35 weeks and $>35$ weeks). Correlation between gestational age vs placenta thickness and expected birth weight vs placental thickness was computedseparately for second and third trimesters. The respective data was plotted on the scattered diagrams and the best fit/trend was shown with a straight line.p value $\leq 0.05$ was considered as statistical

\section{RESULTS}

In the total study group of 99 normal antenatal women, the age ranged between 18 yrs to $39 \mathrm{yrs}$. The mean age was 24.07 years. Majority were in the age group of $21-25$ years (46.5\%). Out of 99 cases studied, anterior placenta was noted in 28 cases, posterior in 30 cases, fundal and lateral in 30 and 11 cases respectively. 


\begin{tabular}{|l|c|c|c|c|c|}
\hline Parameters & No. of subjects & Mean & SD & T Value & P Value \\
\cline { 1 - 4 } Gestational age (weeks) by USG & 84 & 18.97 & 8.02 & 0.039 & 0.969 (NS) \\
\cline { 1 - 4 } Placenta thickness (mm) & 84 & 19.02 & 8.00 & & \\
\hline *Students T Test & Table-1: Gestational age and placental thickness between 11-35 weeks \\
\hline \multicolumn{4}{|l}{}
\end{tabular}

\begin{tabular}{|c|c|c|c|c|c|}
\hline Parameters & No. of subjects & Mean & SD & T Value & P Value \\
\hline Gestational age (weeks) by USG & 15 & 37.53 & 1.45 & \multirow[t]{2}{*}{4.14} & \multirow[t]{2}{*}{$0.001(S)$} \\
\hline Placenta thickness (mm) & 15 & 35.33 & 1.44 & & \\
\hline \multicolumn{6}{|l|}{ *Students T Test } \\
\hline & Table-2: Gestat & nd $\mathrm{pl}$ & $S S>$ & & \\
\hline
\end{tabular}

\begin{tabular}{|l|c|c|c|c|}
\hline No of cases & Mean placental thickness (mm) & Gestational age (wks) & Pearson's correlation coefficient (r) & P Value \\
\hline Second trimester \\
\hline 33 & $19.54 \pm 4.16$ & $19.57 \pm 3.64$ & 0.957 & $0.001^{*}(\mathrm{~S})$ \\
\hline Third trimester & $33.27 \pm 2.82$ & $34.36 \pm 3.51$ & 0.834 & $0.001^{*}(\mathrm{~S})$ \\
\hline 33 & \multicolumn{5}{|l|}{ Table-3: Pearson's correlation values between placenta thicknesses and gestational age } \\
\hline
\end{tabular}

\begin{tabular}{|l|c|c|c|c|}
\hline No of cases & $\begin{array}{c}\text { Mean placental thickness } \\
(\mathbf{m m})\end{array}$ & Estimated fetal weight (gms) & $\begin{array}{c}\text { Pearson's correlation } \\
\text { coefficient (r) }\end{array}$ & P value \\
\hline Second trimester & $19.54 \pm 4.16$ & $317.81 \pm 230.99$ & 0.902 & $0.001^{*}(\mathrm{~S})$ \\
\hline 33 & $33.27 \pm 2.82$ & $2278.27 \pm 695.83$ & 0.856 & $0.001^{*}(\mathrm{~S})$ \\
\hline Third trimester & \multicolumn{5}{|c|}{} \\
\hline 33 & \multicolumn{5}{|c|}{ Table-4: Pearson's correlation values between placenta thicknesses and estimated foetal weight } \\
\hline \multicolumn{4}{|l}{}
\end{tabular}

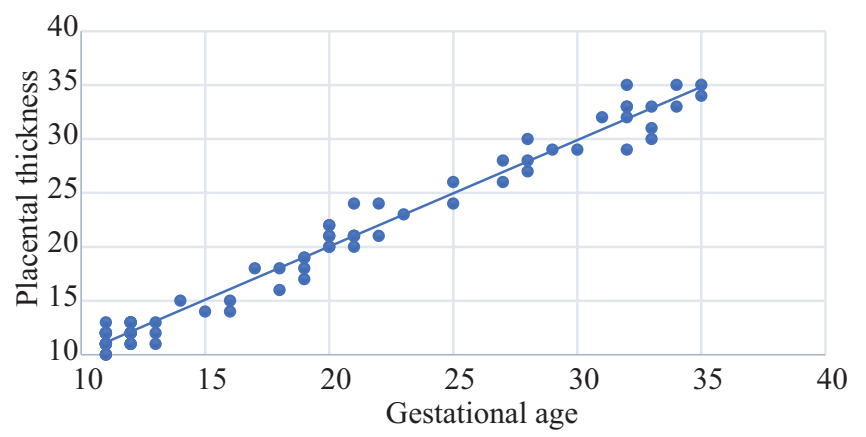

Graph-1: Gestational age and placental thickness between 11-35 weeks

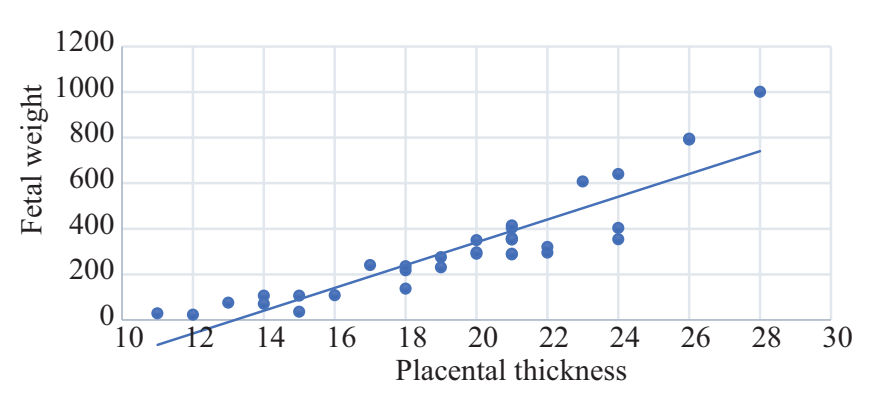

Graph-3: Fetal weight and placental thickness for second trimester

Relationship between gestational age and placental thickness

When placental thickness was measured at each week of gestational age from 11 to 40 weeks, it is observed that placental thickness gradually increased from approximately

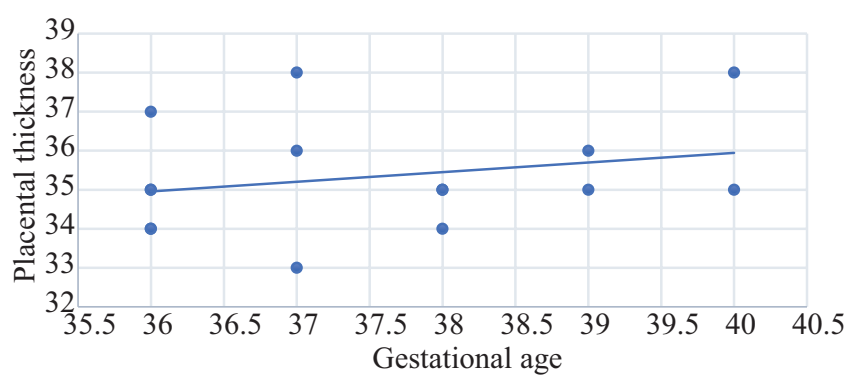

Graph-2: Gestational age and placental thickness $>35$ weeks

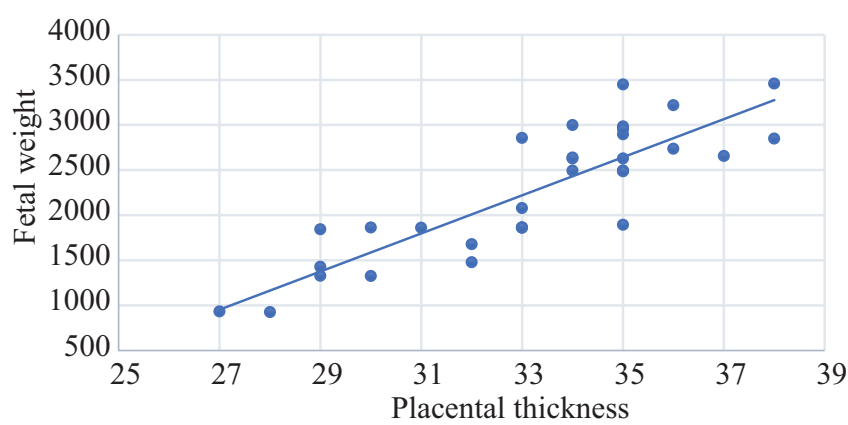

Graph-4: Fetal weight and placental thickness for third trimester

$11.31 \mathrm{~mm}$ at 11 weeks to $36.5 \mathrm{~mm}$ at 40 weeks of gestation. The normal placental 39 thickness was never greater than 38 $\mathrm{mm}$ throughout the pregnancy. Mean $\pm \mathrm{SD}$ of the gestational age (weeks) was observed to be $4021.78 \pm 9.97$ with a range of $11-40$ weeks by USG. The mean \pm SD of placental thickness is $21.49 \pm 9.43$ with a range of $10-38 \mathrm{~mm}$ (table- 1 ). 
At 11-35 weeks of gestational age it was found that there was no statistically significant difference between the mean of gestational age $(18.97 \pm 8.02)$ and placental thickness $(19.02 \pm 8.00)$ as $\mathrm{P}$ value was found to be 0.969 (>0.05) on performing Students $\mathrm{T}$ test. very high positive correlation between gestational age and placental thickness $(\mathrm{r}=0$. 42989*) which was highly significant i.e, ${ }^{*} \mathrm{P}<0.001$ (graph-1). It was found that at $>35$ weeks of gestational age, there is a statistically significant difference between the mean of gestational age $(37.53 \pm 1.45)$ and placental thickness $(35.33 \pm 1.44)$ as $\mathrm{P}$ value was found to be $0.001(<0.05)$ on performing Students $T$ test.poor level of positive correlation between gestational age and placental thickness $(\mathrm{r}=0.248)$ which was also statistically not significant as $\mathrm{P}=0.372$ i.e, $\mathrm{P}>0.05$ (table-2).

Relationship between fetal weight and placental thickness:

The mean placenta thicknesses in millimeters in the second and third trimesters were $19.54+4.16 \mathrm{~mm}$ and $33.27+2.82 \mathrm{~mm}$ respectively. The maximum mean placenta thickness of $36.50+2.12 \mathrm{~mm}$ was recorded at 40 weeks gestation (graph-2,3).

The estimated mean foetal weights in grams in the second and third trimesters were $317.81 \pm 290.00$ gms and $2278.27 \pm 695.83$ gms.

It was observed that, there was a statistically significant positive correlation between sonographic placenta thickness and foetal weight yielding a Pearson's correlation coefficient (r) of $0.902^{*}$ and $0.856^{*}$ for the second and third trimesters respectively within a $\mathrm{P}$ value of $0.001^{*}$ (table-3,4).

\section{DISCUSSION}

Before the advent of prenatal investigation techniques, morphological examination of the placenta was limited to retrospective information and had little influence on pregnancy management. With the improvement of ultrasound equipment, it is now possible to examine the placenta in detail from the beginning of first trimester.

For many years ultrasonologists have described the placenta as a 'static' part in a dynamic system. While all measurements of fetus were related to menstrual age, based on a single cut off point the placental thickness was categorised as normal or abnormal. The present study confirms that placental thickness is a function of age.

Abnormal thickening or thinning must be correlated with other estimates of pregnancy duration. Sonographic measurements of the placenta during pregnancy have been described previously. To determine whether a given placental thickness is normal or abnormal, normal placental thickness must be defined for each week of gestational age throughout pregnancy.

Estimation of the fetal weight, on its own and in relation to the gestational age and placental thickness, can influence obstetric management decisions concerning the timing and route of delivery.

Relationship between gestational age and placental thickness Earliest placental localization was possible at 11 weeks in our study. Before eleven weeks of gestation we observed that the delineation of placental myometrial interface was usually poor and hence it was difficult to measure placental thickness accurately.

In our study, the least placental thickness was $10 \mathrm{~mm}$ at 11 weeks of gestation and highest was $38 \mathrm{~mm}$ at 40 weeks of gestation. At no stage in pregnancy the thickness of placenta was greater than $38 \mathrm{~mm}$. The placental thickness was observed to increase linearly with advancing gestational age from 11 to 40 weeks.

Earliest localization of placenta occurs at around 11 weeks as observed in previous studies also. ${ }^{18}$ However the cut-off of upper limit of normal placental thickness is $40 \mathrm{~mm}$ in a study done by Hoddick et $\mathrm{al}^{19}{ }^{19}$ whereas the maximum placental thickness noted in our study was $38 \mathrm{~mm}$ at 40 weeks of gestation.

When data was separately analysed for 11-35 weeks and $>35$ weeks, it was observed that the placental thickness (in $\mathrm{mm}$ ) increases linearly with increasing gestational age 45 (in weeks) and almost matchesthe gestational age from 11 to 35 weeks of gestation. But from 36 to 40 weeks it was observed that the rate of increase of placental thickness gradually diminished and was less by 1-4 mm compared to gestational age 46 from 11-35 weeks.

The findings of the present study were similar to the observations made by authors of previous studies like Nyberg and Finberg ${ }^{4}$, Hoddick et $\mathrm{al}^{19}$, Mital $\mathrm{P}$ and Hooja $\mathrm{N}^{20}$, AditiTiwari et $\mathrm{al}^{21}$, Nagwani et $\mathrm{a}^{22}$, Anupama Jain et $\mathrm{al}^{23}$, Tanawattanacharoen et $\mathrm{al}^{24}$, Berkowitz et $\mathrm{al}^{25}$, Hellman et $\mathrm{al}^{26}$, Khatri et $\mathrm{al}^{27}$, Baghel et al. ${ }^{28}$

Karthikeyan et $\mathrm{a}^{10}$ have reported an increase in placental thickness by more than $2 \mathrm{~mm}$ in a week in the first trimester by more than $4 \mathrm{~mm}$ in second trimester. However, maximum placental thickness in their study group was $42.2 \mathrm{~mm}$ which is higher than that noted in our study $(38 \mathrm{~mm})$.

Contrary to our study findings, Appiah ${ }^{29}$ in their study found no statistically significant correlation between placental thickness and gestational age $(r=0.09, p>0.05)$. They concluded that an increase in gestational age doesn't have any significant influence on the thickness of the placenta

Relationship between fetal weight and placental thickness In the present study, the mean placenta thicknesses in millimeters in the second and third trimesters were $19.54+4.16 \mathrm{~mm}$ and $33.27+2.82 \mathrm{~mm}$ respectively. The maximum mean placenta thickness of $36.50+2.12 \mathrm{~mm}$ was recorded at 40 weeks gestation. The estimated mean foetal weights in grams in the second and third trimesters were $317.81 \pm 290.00 \mathrm{gms}$ and $2278.27 \pm 695.83 \mathrm{gms}$.

However, in a study done in Nigeria by Ohagwuet $\mathrm{al}^{30}$ the mean placenta thickness in the second and third trimesters were $25.2 \pm 5.6 \mathrm{~mm}$ and $38.4 \pm 7.1 \mathrm{~mm}$ respectively, which were higher as compared to our findings.

In the current study it was found that, there was a statistically significant positive correlation between sonographic placenta thickness and foetal weight yielding a Pearson's correlation coefficient (r) of 0.902 for second trimester and 0.856 for third trimester within a $\mathrm{P}$ value of 0.001 .

This is in accordance with other documented Nigerian studies conducted by $\mathrm{Abu}$ and colleagues ${ }^{31}$ and that carried out by Adeyekun et al. ${ }^{32}$ It is also in consonance with the study conducted by Maryam Afrakhteh et $\mathrm{al}^{33}$ with 250 pregnant women (in Tajrish, Tehran, Iran) and Daskalakis et 
$\mathrm{al}^{34}$ (in Athens, Greece) which are studies performed outside this country.

Similar findings were reported during second and thirdtrimesters showing significant positive correlation placental thickness and fetal weights in studies by Elachel et $\mathrm{al}^{35}$, Ohagwu et $\mathrm{al}^{36}$, De Paula et $\mathrm{al}^{37}$, Daskalis et $\mathrm{al}^{34}$, Sanin et $\mathrm{al}^{38}, \mathrm{Habib}^{39}, \mathrm{Abu}$ et $\mathrm{al}^{31}$, Clapp et $\mathrm{al}^{40}$, Kinare et $\mathrm{al}^{41}$ and previous studies. ${ }^{30,32,42} \mathrm{EFW}$ s showed a progressive increase in value throughout gestation.

\section{CONCLUSION}

Ultrasonographic assessment of placental thickness and estimation of fetal weight is very simple and is useful clinically. It also helps in the evaluation and detection of abnormalities of placenta and 51 intrauterine growth restriction that can significantly influence the outcome of pregnancy.

Placental thickness (in $\mathrm{mm}$ ) was found to correlate linearly with increasing gestational age (in weeks) and was almost matching with it between 11 to 35 weeks of gestation. Hence it can be used as an additional indicator in estimating gestational age especially where the duration of pregnancy is uncertain.

Whereas, it was found that the relationship of placental thickness with gestational age falls marginally and the rate of growth of placental thickness decreased after 35 weeks of gestation.

\section{REFERENCES}

1. TheeraTongsong, PongrakBoonyanurak. Placental thickness in the first half of pregnancy.J Clin Ultrasound. 2004; 32(5): 231-234.

2. Jauniaux E. Placental ultrasonographic measurements: What can we learn and is it worth doing routinely? Ultrasound Obstet Gynecol. 1992; 2(1): 241-242.

3. Ghosh A, Tang MH,Lam YH.Ultrasound measurement of the placental thickness to detect pregnancies affected by homozygous alpha thalassemia-1.Lancet.1994; 344 (5): 988-989.

4. Nyberg DA, Finberg HJ. The placenta, placental membranes and umbilical cord. In: Newburgh DA, Mahony BS, Pretorius DH, Eds. Diagnostic ultrasound of fetal anomalies. St. Louis, Mosby year book publishers. 1990:623-675.

5. Baschat AA, Hecher K. Fetal growth restriction due to placental disease. SeminPerinatol 2004;28 (3): 67-80.

6. Spirt BA, Gordon LP. Sonography of the placenta. In: Fleischer AC, Manning FA, Jeanty P, Romero R, editors. Sonography in obstetrics and gynaecology: principle and practice. Appleton \& Lange. 1996; 173-202.

7. Benirschke K, Kaufmann P. Pathology of the human placenta. $2^{\text {nd }}$ edition. New York: Springer-Verlag. 1990.

8. Sadler TW. Longman's medical embryology. $9^{\text {th }}$ edition. Baltimore, MD: Lippincott Williams and Wilkins. 2004; 117-48.

9. Kuhlmann RS, Warsof S. Ultrasound of the placenta. ClinObstet Gynecol. 1996; 39 (2): 513-34.

10. T Karthikeyan, Ramesh Kumar Subramaniam, WMS Johnson, K Prabhu. Placental Thickness \& its Correlation to Gestational Age \& Foetal Growth Parameters- A Cross Sectional Ultrasonographic Study,
Journal of Clinical and Diagnostic Research. 2012; 6(10): 1732-1735.

11. Hadlock FP, Shah YP, Kanon OJ, Lindsey JF. Fetal crown-rump length: Reevaluation of relation to menstrual age with high-resolution real-time ultrasound. Radiology. 1992; 182 (4): 501

12. Bovicelli L, Orsini LF, Rizzo N. Estimation of gestational age during the first trimester by real time measurement of fetal CRL and BPD. J Clin Ultrasound.1981; 9 (6): 71-75.

13. Robert O, Harris MD, Roberta O, Alexander MD. Ultrasonography of placenta and umbilical cord. In: Peter W Callen, Ed. Ultrasonography in obstetrics and gynecology. $4^{\text {th }}$ edition. Philadelphia, WB Saunders Company. 2000: 597-625.

14. Hadlock FP, Deter RL, Harrist RB, Park SK. Estimating fetal age: computer - assisted analysis of multiple fetal growth parameters. Radiology, 1984; 152:497.

15. Jauniaux E and Campbell S. Placental size. In: Keith Dewbury, HyltonMeire, David Cosgroove, Eds. Ultrasound in obstetrics and gynecology. London, Churchill Livingstone, 1995, 439-440.

16. Campbell S, Wilkin D. Ultrasonic measurements of fetal abdominal circumference in the estimation of fetal weight Br J ObstGynecol 1975; 82(3):689- 697.

17. Vintzileos AM, Campbell WA, Rodies JF. Fetal weight estimation formulas with head, abdominal, femur and thigh circumference measurements. Am J ObstrGynecol 1987; 157(4):410-414.

18. ArunKinare. Fetal environment. Indian J Radiol Imaging 2008;18(4):326-344.

19. Hoddick WK, Mahoney 8S, Callen FW, Filly RA. Placental thickness.J Ultrasound Med. 1985; 4 (1): 479482.

20. Mital P, Hooja N, Mehndiratta. Placental thickness - a sonographic parameter for estimating gestational age of the fetus.Ind J RadiolImag. 2002; 12 (5): 4: 553-554.

21. AditiTiwari, KavitaChandnani. A study to evaluate gestational age with the help of placental thickness. International Journal of Reproduction, Contraception Obstetrics and Gynecology. 2013:2(4):503-505.

22. Nagwani M, Sharma PK, Singh U, Rani A, Mehrotra S. Ultrasonographic measurement of placental thickness and its correlation with gestational age - a crosssectional ultrasonographic study. International Journal of Advanced Research. 2014; 2(6): 354-360.

23. Anupama Jain, Ganesh Kumar, Agarwal U, Kharakwal S. Placental thickness - a sonographic indicator of gestational age. Journal of obstetrics andgynaecologyof India.2001; 51(3): 48-49.

24. Tanawattancharoen S, Manotaya S, Uerpairojkit. Ultrasound measurement of placental thickness in normal singleton pregnancy. Thai J Obstet Gynecol. 2000; 10 (1): 73.

25. Granum PAT, Berkowitz RL, Hobbins JC. The ultrasonic changes in the maturing placenta and their relation to.Fetal pulmonic maturity.Am J Obstet Gynecol. 1979; 133 (5): 915-922.

26. Hellman LM, Kobayashi M, Tolles Wet al. Ultrasonic studies on the volumetric growth of human placenta. Am J Obstet Gynecol.1970;32. 
27. Khatri MH, Ghaffar A, Mahmood R. Estimation of gestational age of the fetus by measuring placental thickness. J Surg Pak. 2005; 10(1): 5-7.

28. PreetiBaghel, Vinita Bahel, RashmiParamhans, PomilaSachdev, SonalOnkar. Correlation of Placental Thickness Estimated by - Ultrasonography with Gestational Age and Fetal Outcome. Indian Journal of Neonatal Medicine and Research. 2015; 3(3): 19-24.

29. Peter KwabenaAppiah. Relationship between the morphology of placenta, Umbilical cord and Perinatal Outcome, 2009.

30. Ohagwu CC, Abu, PO, Ezeokeke UO. andUgwu, AC. Relationship between placental thickness and growth parameters in normal Nigerian fetuses. African Journal of Biotechnology 2009;8 (2):133-138.

31. P. O.Abu, C. C. Ohagwu, J.C Eze, K Ochie. Correlation Between Placental Thickness and Estimated Fetal Weight In Nigerian Women. Ibnosina Journal of Medicine and Biomedical Sciences 2009;1 (1):80-85.

32. Adeyekun AA, Ikubor JE. Relationship between twodimensional ultrasound measurement of placental thickness and estimated fetal weight. Sahel Med J 2015;18(1):4-8

33. Maryam Afrakhteh, Aida Moeini, MortezaSaneiTaheri, Hamid Reza Haghighatkhah. Correlation between placental thickness in the second and third trimester and fetal weight, Rev Bras Ginecol Obstet. 2013; 35(7):317-22.

34. Daskalakis G, Papadopoulos D, Anastasakis E, Theodora M, Papuntoniou N, Mesogitis S, et al. Placenta Dimensions in early 2nd trimester. Special Issue: 18th World congress on ultrasound in obstetrics and Gynaecology. ISUOG: John Wiley and sons, Ltd; 2008; 32 (3): 428.

35. Elachal U, Ezra Y, Levi Y, Bar-Oz B, Yanai N, Nadjari M. Sonographically thick placenta: a marker for increased perinatal risk - a prospective cross - sectional study. Placenta 2000; 21(2-3):268-72.

36. Ohagwu CC, Oshiotse Abu P, EffongUdoh B. Placental thickness: a sonographic indicator of gestational age in normal singleton pregnancies in Nigerian women. Internet Journal of Medical Update. 2009;4(2):9-14.

37. De Paula CF, Ruano R, Campos JA, Zugaib M.Placental volumes measured by 3 -dimensional ultrasonography in normal pregnancies from 12 to 40 weeks' gestation. J Ultrasound Med 2008;27 (6):1583-90.

38. Sanin LH, López SR, Olivares ET, Terrazas MC, Silva MA, Carrillo ML. Relation between birth weight and placenta weight. Biol Neonate 2001;80 (3):113-7.

39. Habib FA. Prediction of low birth weight infants from ultrasound measurement of placental diameter and placental thickness. Ann Saudi Med. 2002; 22(5-6): 312-14.

40. Clapp JF, Rizk KH, Appleby-Wineberg SK, Crass JR. Second trimester placental volumes predicts birth weight at term. J SocGynecollnvestig. 1995;2(1):19-22.

41. Kinare AS, Natekar AS, Chinchwadkar MC, Yajnik CS, Coyaji KJ, Fall CH, et al. Low mid pregnancy placental volume in rural Indian women: a cause for low birth weight? Am J Obstet Gynecol. 2000;182(2):443-8.

42. Adeyekun AA. Ultrasound assessment of placental thickness and its correlation with gestational age in normal pregnancy: A preliminary report. Sahel Med J 2012;15 (1):10-5.

\section{Source of Support: Nil; Conflict of Interest: None}

Submitted: 13-07-2019; Accepted: 15-06-2019; Published online: 04-09-2019 